Feature Article

\title{
Evaluating Generic Pantropical Allometric Models for the Estimation of Above-Ground Biomass in the Teak Plantations of Southern Western Ghats, India
}

\author{
S. Sandeep ${ }^{1 *}$, M. Sivaram ${ }^{2}$, K.K. Sreejesh ${ }^{1}$ and T.P. Thomas ${ }^{1}$ \\ ${ }^{1}$ Kerala Forest Research Institute, Peechi, India \\ ${ }^{2}$ Southern Regional Station, National Dairy Research Institute, Bangaluru, India
}

\begin{abstract}
The use of suitable tree biomass allometric equations is crucial for making precise and nondestructive estimation of carbon storage and biomass energy values. The aim of this research was to evaluate the accuracy of the most commonly used pantropical allometric models and site-specific models to estimate the above-ground biomass (AGB) in different aged teak plantations of Southern Western Ghats of India. For this purpose, the AGB data measured for 70 trees with diameter $\geq 10 \mathrm{~cm}$ from different aged teak plantations in Kerala part of Southern Western Ghats following destructive procedure was used. The results show that site specific models based on a single predictor variable diameter at breast height ( $\mathrm{dbh}$ ), though simple, may grossly increase the uncertainty across sites. Hence, a generic model encompassing dbh, height and wood specific gravity with sufficient calibration taking into account different forest types is advised for the tropical forest systems. The study also suggests that the commonly used pantropical models should be evaluated for different ecosystems prior to their application at national or regional scales.
\end{abstract}

Keywords: allometric models, above ground biomass, Western Ghats

\section{Introduction}

Estimation of volume, biomass and carbon stocks supports several applications from the commercial exploitation of timber to the global carbon cycle. Especially, in the latter context, the estimation of tree biomass with sufficient accuracy is essential to determine annual changes of carbon stored in particular ecosystems. Such estimations are the core of carbon sequestration projects (sink projects) dealing with the accumulation and long-term storage of atmospheric carbon in vegetation and soil organic matter. These projects give a better understanding of nature's carbon sinks, and the valuable information and evidence generated therein will help addressing the physical, natural, social and economic aspects of climate change in a more factual way.

Tropical forests, which constitute $60 \%$ of world forests and $43 \%$ of terrestrial net primary productivity (Dixon et al., 1994), dominate the role of forests in the global carbon flux and stocks, and hence demand great attention with respect to carbon policies and estimations. In spite of their

\footnotetext{
* Correspondence: sandeepagri@gmail.com

Tel: +919495660212

ISSN 2235-9370 Print/ISSN 2235-9362 Online (C) University of Sri Jayewardenepura
} 
importance to the carbon cycle, there is little information on the carbon budgets of tropical forest systems in South Asia. Efficient and accurate national systems for measurement, reporting and verification (MRV) systems are required in the region to properly assess carbon stocks and support international climate change efforts. The use of suitable allometric equations is a crucial step in such endeavours, making precise and non-destructive estimation of above and below ground biomass and carbon storage in the region.

Allometry, generally relates some non-easy to measure tree characteristics (i.e., volume, biomass) from easily collected data such as dbh (diameter at breast height, also denoted as D), total height, or tree age and provides relatively accurate estimates. Despite their apparent simplicity, these models have to be built carefully, using the latest regression techniques. Tree growth parameters vary considerably with species, site quality, location, climatic regimes, altitude etc. and therefore becomes necessary to obtain accurate and precise tree allometric estimates in order to improve understanding of the role of these carbon sinks in global carbon cycle. An unsuitable application of allometric equation may lead to considerable bias in carbon stocks estimations (Henry, 2013). Although, large number of allometric equations for estimating above-ground biomass (AGB) have been published in South Asia during the last decades (Sandeep et al., 2014), the pantropical models developed by Chave et al. (2005) are widely considered to be the best current approximation for sites for which local equations are not available (Clark, 2007). However, the predictive power of these global models differs among sites (Chave et al., 2005). For this reason, the evaluation of the accuracy of these models with new data and in different geographic locations is needed.

Due to the uncertainties in the generic pantropical models, a simplest and most practical approach is based only upon tree diameter at breast height (Basuki et al., 2009; Alvarez et al., 2012). However, scaling of $\mathrm{dbh}$ alone based models to a regional or global scale may have greater uncertainties than more complex models (West et al., 1999; Zianis, 2008). Inclusion of wood density and tree height has proved to improve biomass estimations considerably (Brown et al., 1989; Chave et al., 2006; ter Steege et al., 2006; Wang et al., 2006; Patiño et al., 2009). The present work aims to evaluate the accuracy of the most commonly employed pantropical allometric models and simple dbh alone based site specific models to estimate AGB in different aged teak plantations of Southern Western Ghats.

\section{Materials and Methods}

\subsection{Tree harvesting and biomass estimation}

Teak plantations in different thinning regimes and at final felling were surveyed in Nilambur Forest Division of Kerala state, India and seven sites corresponding to the prescribed felling schedule were selected for the study. Presently the thinning operations are performed in teak plantations at the ages of 5, 10, 15, 20, 30, and 40 years and the plantations are clear felled at 50 years. Each site represents a specific age. Ten randomly selected trees were felled at each of these sites and were used for biomass estimations. Before felling, dbh was measured at $1.37 \mathrm{~m}$ or above buttresses.

The total heights $(\mathrm{H})$ of the trees were measured on the ground using a measuring tape from the base towards the apex of the crown. Felled trees were separated into their components (trunk, branches and foliage) and were directly weighed in the field to assess the fresh weight. Root systems of the selected trees in each site were excavated manually by starting at the stump and following the roots to possible limits and weighed. Sufficient samples of wood, branches and roots were taken from each tree to determine their moisture contents. Biomass of various compartments were worked out by estimating 
dry matter of samples by oven drying to constant weight and extrapolation to the whole biomass, which are referred to as measured biomass in this article.

\subsection{Evaluation of existing allometric models}

The accuracy of the pantropical allometric models developed by Brown et al. (1989), Chave et al. (2005), and Zianis (2008) (Table 1) were evaluated by calculating the relative error in the predicted biomass to measured biomass for each site. The relative error (RE) for above-ground biomass (AGB) was calculated using equation 1.

Table1: Evaluated pantropical models for estimating the above-ground biomass (dry mass) of tropical trees from their diameter $(\mathrm{cm})$, height $(\mathrm{m})$, and wood density $\left(\mathrm{g} \mathrm{cm}^{-3}\right)$.

\begin{tabular}{lll}
\hline \multicolumn{1}{c}{ Model code } & \multicolumn{1}{c}{ Allometric models } & \multicolumn{1}{c}{ Source } \\
\hline Chave Type I & $\exp \left(-2.187+0.916 \ln \left(\rho \mathrm{D}^{2} \mathrm{H}\right)\right)=0.112\left(\rho \mathrm{D}^{2} \mathrm{H}\right)^{0.916}$ & Chave et al. (2005) \\
Chave Type II & $\exp \left(-2.977+0.916-\ln \left(\rho \mathrm{D}^{2} \mathrm{H}\right)\right)=0.0509\left(\rho \mathrm{D}^{2} \mathrm{H}\right)$ & Chave et al. (2005) \\
Chave Type III & $\left.\left.\exp \left(-2.557+0.940 \ln \left(\rho \mathrm{D}^{2} \mathrm{H}\right)\right)\right)=0.0776\left(\rho \mathrm{D}^{2} \mathrm{H}\right)\right)^{0.940}$ & Chave et al. (2005) \\
Brown & $\exp \left(-2.4090+0.9522 \operatorname{In}\left(\rho \mathrm{D}^{2} \mathrm{H}\right)\right)$ & Brown et al. (1989) \\
Zianis & $0.1424 \mathrm{D}^{2.3679}$ & Zianis (2008) \\
\hline
\end{tabular}

$$
R E=\left(A G B_{\text {predicted }}-A G B_{\text {measured }}\right) / A G B \text { measured }
$$

Following Chave et al. (2005), the overall biases were evaluated by examining the mean relative error $(\%)$, and the accuracy was evaluated by examining the standard deviation of relative error (\%) across sites, which represented the overall predictive power of the regression (Chave et al., 2005).

At a local scale, the simplest models for assessing AGB are based upon tree dbh (Sierra et al., 2007; Litton and Kauffman, 2008; Basuki et al., 2009). Five teak specific allometric models (models 17 in Table 2) based only upon dbh, developed in Kerala, were evaluated for their accuracy and predictive capacities. However, a simple geometrical argument suggests that the total AGB of a tree with diameter $\mathrm{D}$ should be proportional to the product of wood specific gravity (oven-dry wood over green volume, denoted by $\rho)$, times trunk basal area $\left(B A=\pi D^{2} / 4\right)$, times total tree height $(H)$. Hence, the relationship should hold across forests as in equation 2 :

$$
G B=F \times \rho \times\left(\pi \times D^{2} / 4\right) \times H
$$

Table 2: Tree biomass models for predicting above-ground biomass (y) of teak plantations in Kerala part of Southern Western Ghats.

\begin{tabular}{ll}
\hline Models & Allometric models \\
\hline Model-1 & $\log (\mathrm{y})=1.606+0.197 \log (\mathrm{D})$ \\
Model-2 & $\log (\mathrm{y})=0.636+1.265 \log (\mathrm{D})$ \\
Model-3 & $\log (\mathrm{y})=0.567+1.367 \log (\mathrm{D})$ \\
Model-4 & $\log (\mathrm{y})=0.479+1.374 \log (\mathrm{D})$ \\
Model-5 & $\log (\mathrm{y})=-0.150+1.809 \log (\mathrm{D})$ \\
Model-6 & $\log (\mathrm{y})=1.736 \log (\mathrm{D})$ \\
Model-7 & $\log (\mathrm{y}))=0.685+1.376 \log (\mathrm{D})$ \\
Model-8 & $\mathrm{y}=\mathrm{F} \mathrm{x} \rho \mathrm{x}\left(\pi \mathrm{D}^{2} / 4\right) \times \mathrm{H}$ \\
\hline
\end{tabular}


Model 8 tries to capture this argument and hence evaluates the efficacy of equations with wood density and height factors rather than dbh alone. The multiplicative coefficient $F$ depends on tree taper and was taken as 0.06 as predicted by Cannell (1984) for broad leaved species (Chave, 2005).

\section{Results and Discussion}

The results show that there was a linear increase in dbh of tress with age (Figure 1) and there was about $8 \mathrm{~cm}$ decadal increases in dbh of teak trees with age. On an average, teak plants yielded $1052.2 \mathrm{~kg} /$ tree (AGB+roots) of which $60.4 \%$ was contributed by wood, $5.6 \%$ by bark, $17.4 \%$ by branches and $16.5 \%$ by roots (data not shown). As percent of AGB, root contribution was $20 \%$. Though root biomass is as important as shoot in carbon stock estimations, there were very few documents on root growth parameters (Sandeep et al., 2014). As a proportion of AGB, roots were found to contribute $14 \%-27 \%$ to the total biomass of teak. The decline in ratio of root:AGB in teak indicates accumulation of carbon in above-ground portions alone after 30 years.

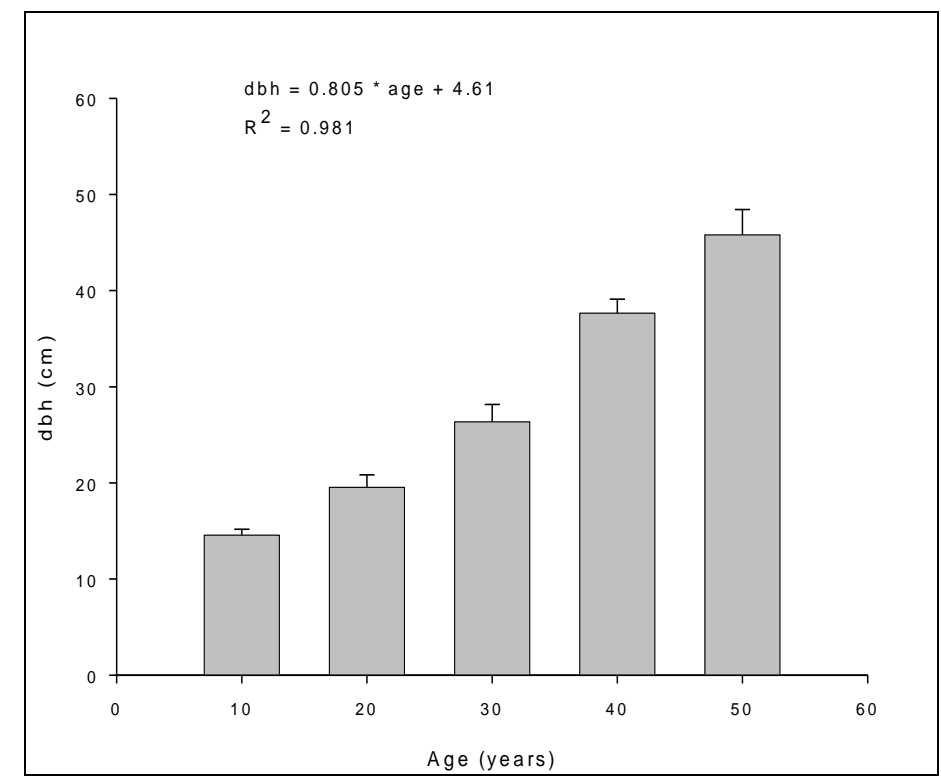

Figure 1: Trends in mean dbh of trees with age in teak plantations of Kerala part of Southern Western Ghats.

Overall, the Chave type of Table 1 (2005; hereafter Chave I) model had the lowest bias for estimating the total average AGB in different sites (-1.5\%) (Table 3). However, this model was quite unstable at the site scale $(22.5 \%)$. The Type II model of Chave et al. (2005; hereafter Chave II) at the site scale underestimated the average AGB of the forests within acceptable limits $(-5.0 \%)$. The model of Brown et al. (1989; hereafter Brown) had a similar but positive bias in magnitude at the site scale (9.1\%) when compared with Chave I and II but highest uncertainty (26.9\%) among the tested models.

Zianis model (2008; hereafter Zianis) though underestimated AGB than Brown and Chave (I and II) models at the site scale, had the lowest uncertainty. The Type III model of Chave et al. (2005; hereafter Chave III), tended to strikingly underestimate the AGB across sites with respect to Chave I and II and Brown models and had very low stability. The allometric model developed by Zianis included only dbh as an explanatory variable. Earlier West et al. (1999) and later Chambers et al. (2001) showed that AGB does not follow a simple power law scaling relation with stem diameter. The 
instability in models with $\mathrm{H}, \rho$ and forest types may be due to some fundamental differences in the way $\rho$ was assessed and included in the study. In the present analyses, inferred $\rho$ values were used from the literature which have several disadvantages in comparison to field measurement data because they add an additional amount of uncertainty to the models (Chave et al., 2005).

Table 3: Variation in root biomass to AGB ratio in teak plantations in Kerala part of Southern Western Ghats.

\begin{tabular}{ccccc}
\hline Age & \multicolumn{2}{c}{ dbh $(\mathrm{cm})$} & AGB $(\mathrm{kg} /$ tree $)$ & Root to AGB ratio \\
\hline & Min & Max & & \\
10 & 12.2 & 19.43 & 133.31 & 0.16 \\
20 & 13.69 & 27.39 & 189.21 & 0.26 \\
30 & 20.38 & 36.62 & 320.97 & 0.27 \\
40 & 32.80 & 44.59 & 621.04 & 0.21 \\
50 & 36.31 & 59.87 & 878.47 & 0.20 \\
& Mean & & 340.99 & 0.21 \\
\hline
\end{tabular}

The inferred $\rho$ data assumed a unique value across the age and dbh classes. In addition to the concerns related to $\rho$ measurement, the changes in the H:D relationship observed in the data set determined by the site variation were not detected by Brown and Chave model, further restricting their accuracy. All the pantropical models evaluated gave a gross underestimation for dbh values $<20 \mathrm{~cm}$ and overestimation $>40 \mathrm{~cm}$. From the preliminary analysis neither of the evaluated pantropical models could be recommended for application at national or regional scales.

The species-specific models used in this study also had higher biases, but were more stable (except models 1, 7 and 8). Of the species-specific models at the individual scale, model 3 that used the dbh ranges $10-25 \mathrm{~cm}$ was statistically the best of all of the models evaluated (Table 5). The study could not conclusively establish that using a single predictor 'dbh' in allometric models is an accurate AGB estimation method across different sites, though simple and practical.

Table 4: Relative percent error of pantropical equations in evaluating above-ground biomass in different age teak plantations in Kerala part of Southern Western Ghats.

\begin{tabular}{ccccrr}
\hline Age (Years) & Chave Type I & Chave Type II & ChaveType III & Brown & Zianis \\
\hline 5 & -38.9 & -52.8 & -50.7 & -38.3 & -49.9 \\
10 & -44.3 & -53.9 & -54.2 & -42.1 & -39.1 \\
15 & -46.7 & -53.8 & -55.6 & -43.5 & -52.2 \\
20 & 0.4 & -9.3 & -15.4 & 8.3 & -14.3 \\
30 & 6.6 & 2.1 & -8.6 & 18.0 & 1.1 \\
40 & 49.7 & 56.7 & 31.6 & 72.1 & 23.1 \\
50 & 62.5 & 75.8 & 44.2 & 89.5 & 39.0 \\
Mean (\%) & -1.5 & -5.0 & -15.5 & 9.1 & -13.2 \\
SD $(\%)$ & 22.5 & 25.8 & 20.3 & 26.9 & 15.0 \\
\hline
\end{tabular}

Model 8 that included dbh, wood density and height showed good performance at the individual site scale at all the evaluated dbh ranges but had very high instability, hence further refinement suggested. The form factor $F$ in model 8 was assumed to be equal to 0.6 for this study, close to the predictions of Dawkins (1961) and Gray (1966) for broadleaf tree species. However, engineering 
arguments (McMahon and Kronauer, 1976) suggest that the form factor is not a constant but trees taper as a powerlaw along the main stem.

Table 5: Relative percent error of site specific equations in evaluating above-ground biomass in teak plantations in Kerala part of Southern Western Ghats.

\begin{tabular}{ccc}
\hline Models & $\begin{array}{c}\text { Relative Error } \\
(\%)\end{array}$ & $\begin{array}{c}\text { Standard } \\
\text { Deviation }\end{array}$ \\
\hline Model - 1 & -68.76 & 20.2 \\
Model - & -19.42 & 16.3 \\
Model - 3 & -5.69 & 16.2 \\
Model - 4 & -21.30 & 13.4 \\
Model - 5 & -26.82 & 13.2 \\
Model - 6 & -18.20 & 13.2 \\
Model - 7 & 27.30 & 21.6 \\
Model - 8 & -6.15 & 55.7 \\
\hline
\end{tabular}

The assumption of a constant $F$ will grossly reduce the stability of model 8 across dbh and height classes. Wood specific gravity is another important predictive variable used in model 8 . Baker et al. (2004) have reported that ignoring variations in wood density would result in poor overall prediction of allometric models. Several workers (Brown et al. 1989; Nelson et al. 1999; Chave et al. 2003; Baker et al. 2004) have recommended using a species-level average or a stand-level average of wood density as direct tree density measurements are seldom available. Thus a model encompassing D, H and $\rho$ with sufficient calibration for different forest types is advised for the tropical forest systems.

\section{Conclusion}

AGB quantifications have major implications in assessing ecosystems capacity to sequester carbon. Chave I model had the lowest bias for estimating the total average AGB in different sites, but was quite unstable at the site scale. Zianis model though underestimated AGB than Brown and Chave (I and II) models at the site scale, had the lowest uncertainty. All the pantropical models evaluated gave a gross underestimation for dbh values $<20 \mathrm{~cm}$ and overestimation $>40 \mathrm{~cm}$. From the present study, neither of the evaluated pantropical models could be recommended for indiscriminate application at national or regional scales. Of the species specific models at the individual scale, model 8 that included dbh, wood density and height showed good performance at the individual site scale at all the evaluated dbh ranges but had high instability. The study concludes that a model encompassing $\mathrm{D}, \mathrm{H}$ and $\rho$ is advised for the tropical forest systems. The model can be made more stable by proper substitution of $\rho$ and form factors considering the age structure and forest types. In this regard, further work is needed to evaluate other available allometric equations besides finding out suitable $\rho$ and form factors.

\section{References}

Alvarez, E., Duque, A., Saldarriaga, J., Cabrera, K., de las Salas, G., del Valle, I., Lema, A., Moreno, F., Orrego, S. and Rodríguez, L. 2012. Tree above-ground biomass allometries for carbon stocks estimation in the natural forests of Colombia. Forest Ecology and Management, 267: 297-308.

Baker, T.R., Phillips, O.L., Malhi, Y., Almeida, S., Arroyo, L., Di Fiore, A., Erwin, T., Higuchi, N., Killeen, T.J., Laurance, S.G., Laurance, W.F., Lewis, S.L., Lloyd, J., Monteagudo, A., Neill, D.A., Patino, S., Pitman, N.C.A., Silva, J.N.M. and Vasquez Martinez, R., 2004. Variation in wood density determines spatial patterns in Amazonian forest biomass. Global Change Biology, 10(5): 545-562. 
Basuki, T.M., van Laake, P.E., Skidmore, A.K. and Hussin, Y.A. 2009. Allometric equations for estimating the above-ground biomass in tropical lowland Dipterocarp forests. Forest Ecology and Management, 257: 1684-1694.

Brown, S., Gillespie, A. and Lugo, A.E. 1989. Biomass estimation methods for tropical forest with applications to forest inventory data. Forest Science, 35(4): 881-902.

Cannell, M.G.R. 1984. Woody biomass of forest stands. Forest Ecology and Management, 8: 299-312.

Chambers, J.Q., dos Santos, J., Ribeiro, R.J. and Higuchi, N.2001. Tree damage, allometric relationships, and above-ground net primary production in central Amazon forest. Forest Ecology and Management, 152: 73-84.

Chave, J., Condit, R., Lao, S., Caspersen, J.P., Foster, R.B. and Hubbell, S.P. 2003. Spatial and temporal variation in biomass of a tropical forest: results from a large census plot in Panama. Journal of Ecology, 91(2): 240-252.

Chave, J., Andalo, C., Brown, S., Cairns, M.A., Chambers, J.Q., Eamus, D., Folster, H., Fromard, F., Higuchi, N., Kira, T., Lescure, J.P., Nelson, B.W., Ogawa, H., Puig, H., Riéra, B. and Yamakura, T. 2005. Tree allometry and improved estimation of carbon stocks and balance in tropical forests. Oecologia, 145: 87-99.

Chave, J., Muller-Landau, H.C., Baker, T.R., Easdale, T.A., ter Steege, H. and Webb, C.O. 2006. Regional and phylogenetic variation of wood density across 2,456 neotropical tree species. Ecological Applications, 16(6): 2356-2367.

Clark, D.A. 2007. Detecting Tropical Forests' Responses to Global Climatic and Atmospheric Change: Current Challenges and a Way Forward. Biotropica, 39(1): 4-19.

Dawkins, H.C. 1961. Estimating total volume of some Caribbean trees. Caribbean Forester, 22: 62-63.

Dixon, R.K., Brown, S., Solomon, R.A., Trexler, M.C. and Wisniewski, J. 1994. Carbon pools and flux of global forest ecosystems. Science, 263: 185-190.

Henry M., Bombelli A., Trotta C., Alessandrini A., Birigazzi L., Sola G., Vieilledent G., Santenoise P., Longuetaud F., Valentini R., Picard N. and Saint-André L. 2013. Glob Allome Tree: international platform for tree allometric equations to support volume, biomass and carbon assessment. iForest - Biogeosciences and Forestry, 6: 326-330.

Litton, C.M. and Kauffman, J.B. 2008. Allometric models for predicting aboveground biomass in two widespread woody plants in Hawaii. Biotropica, 40(3): 313-320.

Luizão, F., Meir, P., Monteagudo, A., Neill, D., Núñes-Vargas, P., Peñuela, M.C., Pitman, N., Priante Filho, N., Prieto, A., Panfil, S.N., Rudas, A., Salomão, R., Silva, N., Silveira, M., Soares de Almeida, S., Torres-Lezama, A., Vásquez-Martínez, R., Vieira, I., Malhi, Y. and Phillips, O.L. 2009. Branch xylem density variations across the Amazon Basin. Biogeosciences, 6: 545-568.

McMahon, T.A. and Kronauer, R.E. 1976. Tree structures: deducing the principles of mechanical design. Journal of theoretical Biology, 59(2): 443-466.

Nelson, B.W., Mesquita, R., Pereira, J.L.G., de Souza, S.G.A., Batista, G.T. and Couto, L.B. 1999. Allometric regressions for improved estimate of secondary forest biomass in the central Amazon. Forest Ecology and Management, 117: 149-167.

Sandeep, S., Sivaram, M., Henry, M. and Birigazzi, L. 2014. Inventory of volume and biomass tree allometric equations for South Asia.KFRI, Peechi, India. UN-REDD Programme MRV report, 15, Food \& Agriculture Organization of the United Nations, Rome, Italy.

Sierra, C.A., del Valle, J.I., Orrego, S.A., Moreno, F.H., Harmon, M.E., Zapata, M., Colorado, G.J., Herrera, M.A., Lara, W., Restrepo, D.E., Berrouet, L.M., Loaiza, L.M. and Benjumea, J.F. 2007. Total carbon stocks in a tropical forest landscape of the Porce region, Colombia. Forest Ecology and Management, 243: 209-309. 
ter Steege, H., Pitman, N.C.A., Phillips, O.L., Chave, J., Sabatier, D., Duque, A., Molino, J.F., Pr'evost, M.F., Spichiger, R., Castellanos, H., von Hildebrand, P. and Vásquez, R. 2006. Continental-scale patterns of canopy tree composition and function across Amazonia. Nature, 443: 444-447.

Wang, X., Fang, J., Tang, Z. and Zhu, B. 2006. Climatic control of primary forest structure and DBH height allometry in Northeast China. Forest Ecology and Management, 234: 264-274.

West, G.B., Brown, J.H., Enquist, B.J., 1999. A general model for the structure and allometry of plant vascular system. Nature, 400: 664-667.

Zianis, D. 2008. Predicting mean above ground forest biomass and its associated variance. Forest Ecology and Management, 256: 1400-1407. 